\title{
Strontium:calcium ratios in statoliths of Japanese common squid Todarodes pacificus (Cephalopoda: Ommastrephidae) as indicators of migratory behavior
}

\author{
Yuzuru Ikeda $^{1, *}$, Nobuaki Arai $^{2}$, Hideaki Kidokoro $^{3}$, Wataru Sakamoto ${ }^{4,5}$ \\ ${ }^{1}$ Brain Science Institute, RIKEN, Wako, Saitama 351-0198, Japan \\ ${ }^{2}$ Graduate School of Informatics, Kyoto University, Kyoto 606-8501, Japan \\ ${ }^{3}$ Japan Sea National Fisheries Research Institute, Niigata 951-8121, Japan \\ ${ }^{4}$ Graduate School of Agriculture, Kyoto University, Kyoto 606-8502, Japan \\ ${ }^{5}$ Present address: Fisheries Laboratory of Kinki University, Shirahama, Wakayama 649-2211, Japan
}

\begin{abstract}
Ontogenetic variation in the strontium:calcium (Sr:Ca) ratios was measured in statoliths of the Japanese common squid Todarodes pacificus. Two different geographical groups of $T$. pacificus inhabit the Sea of Japan; these groups are separated by the Subarctic Front during the summer. Element ratios were measured with a wavelength-dispersive spectrometer for 11 individuals from a cold-water subarctic region, which harbors large squid (Subarctic Group), for 12 individuals from a warm-water region, which harbors smaller squid (Tsushima Group), and for 2 individuals from the Subarctic Front. The squid ranged from 190 to $218 \mathrm{~mm}$ in mantle length (ML) and were 191 to $262 \mathrm{~d}$ old. Similar measurements were obtained for 12 tagged T. pacificus (187 to $259 \mathrm{~mm} \mathrm{ML;} 214$ to $312 \mathrm{~d}$ old) that were released and recovered in the Subarctic and the Tsushima Current between June and August 1997 (tagging duration 5 to $>40$ d). Ontogenetic variation in $\mathrm{Sr}$ :Ca ratios from hatchlings to sub-adults differed between the 2 geographical groups. Sr:Ca ratios were high at hatching followed by a drastic decrease up to $10 \mathrm{~d}$ of age for both groups. These ratios increased until $40 \mathrm{~d}$ of age, continuing at high levels until around $150 \mathrm{~d}$, when they decreased in all specimens of the Tsushima Group. In the Subarctic Group, however, the variations in $\mathrm{Sr}$ :Ca ratios differed between individuals. $\mathrm{Sr}: \mathrm{Ca}$ ratios at the age when squid recruited to either the Subarctic or the Tsushima Current were similar. These differences reflect the different spawning grounds and transport routes of the 2 groups. Thermal history was recorded from the statoliths of tagged individuals, and small fluctuations and seasonal variations in the $\mathrm{Sr}$ :Ca ratios were observed. These correspond to diel vertical movements and endogenous rhythms of the squid, and the formation and movements of the coldwater layer in their habitat.
\end{abstract}

KEY WORDS: Japanese common squid $\cdot$ Statoliths $\cdot$ Sr:Ca ratios $\cdot$ Migration $\cdot$ Sea of Japan

\section{INTRODUCTION}

The Japanese common squid Todarodes pacificus migrates between the East China Sea and the Okhotsk Sea during a $1 \mathrm{yr}$ life span (Okutani 1983). The Sea of Japan, the main habitat of T. pacificus, is divided by the Subarctic Front into 2 regions: the Subarctic (a cold-water region) and the Tsushima Current (a warm- water region). The specimens of $T$. pacificus that inhabit these 2 regions during the summer form 2 distinct groups - the Subarctic Group and the Tsushima Group. The Subarctic Group comprises large individuals, which feed predominantly on crustaceans (Parathemisto japonica). The Tsushima Group consists of smaller individuals that feed on mesopelagic fish (Maurolicus muelleri japonica) (Ito et al. 1965, Oki- 
Table 1. Todarodes pacificus. Summary of collection data for Study 1 (investigation of migratory routes). Maturity determined according to Ikeda et al. (1991a,b). ML: mantle length; F: female; M: male

\begin{tabular}{|c|c|c|c|c|c|c|c|}
\hline Specimen & ML (mm) & Body wt.(g) & Sex & Maturity & Age $(d)$ & Birth month & Measurement type \\
\hline \multicolumn{8}{|c|}{ Stn 1: Tsushima Current $\left(38^{\circ} 42^{\prime} \mathrm{N}, 138^{\circ} 25^{\prime} \mathrm{E}\right), 24$ June 1997} \\
\hline $1-1$ & 205 & 145 & $\mathrm{~F}$ & Immature & 198 & Dec & Line \\
\hline $1-3$ & 215 & 188 & $\mathrm{~F}$ & Immature & 215 & Nov & Line \\
\hline $1-5$ & 201 & 193 & $\mathrm{~F}$ & Immature & 228 & Nov & Quantitative \\
\hline $1-8$ & 200 & 157 & M & Maturing & 259 & Oct & Line \\
\hline \multicolumn{8}{|c|}{ Stn 5: Subarctic Front $\left(40^{\circ} 00^{\prime} \mathrm{N}, 137^{\circ} 00^{\prime} \mathrm{E}\right), 25$ June 1997} \\
\hline $5-2$ & 211 & 201 & $\mathrm{~F}$ & Immature & 262 & Oct & Quantitative \\
\hline $5-3$ & 215 & 203 & $\mathrm{~F}$ & Immature & 231 & Nov & Quantitative \\
\hline \multicolumn{8}{|c|}{ Stn 8: Subarctic Region $\left(40^{\circ} 40^{\prime} \mathrm{N}, 135^{\circ} 00^{\prime} \mathrm{E}\right), 26$ June 1997} \\
\hline $8-2$ & 215 & 212 & $\mathrm{~F}$ & Immature & 232 & Nov & Line \\
\hline $8-3$ & 204 & 154 & $\mathrm{~F}$ & Immature & 233 & Nov & Line \\
\hline $8-8$ & 208 & 191 & M & Immature & 209 & Nov & Line \\
\hline $8-9$ & 215 & 193 & $\mathrm{M}$ & Immature & 217 & Nov & Line \\
\hline \multicolumn{8}{|c|}{ Stn 11: Subarctic Region $\left(42^{\circ} 00^{\prime} N, 135^{\circ} 40^{\prime} \mathrm{E}\right), 27$ June 1997} \\
\hline $11-2$ & 190 & 162 & $\mathrm{~F}$ & Immature & 254 & Oct & Quantitative \\
\hline $11-3$ & 212 & 203 & $\mathrm{~F}$ & Immature & 197 & Dec & Line \\
\hline $11-4$ & 201 & 152 & $\mathrm{~F}$ & Immature & 238 & Nov & Quantitative \\
\hline $11-5$ & 212 & 212 & $\mathrm{~F}$ & Immature & 223 & Nov & Quantitative \\
\hline $11-6$ & 206 & 209 & $\mathrm{M}$ & Maturing & 203 & Dec & Line \\
\hline $11-7$ & 209 & 176 & $\mathrm{M}$ & Immature & 191 & Dec & Line \\
\hline \multicolumn{8}{|c|}{ Stn 22: Subarctic Region $\left(40^{\circ} 40^{\prime} \mathrm{N}, 135^{\circ} 00^{\prime} \mathrm{E}\right), 30$ June 1997} \\
\hline $22-4$ & 201 & 165 & $\mathrm{M}$ & Immature & 208 & Dec & Line \\
\hline \multicolumn{8}{|c|}{ Stn 62: Tsushima Current (3940' N, 13900' E), 11 July 1997} \\
\hline $62-2$ & 210 & 233 & $\mathrm{~F}$ & Immature & 227 & Nov & Line \\
\hline $62-5$ & 210 & 176 & $\mathrm{~F}$ & Immature & 216 & Dec & Line \\
\hline $62-7$ & 207 & 190 & M & Maturing & 227 & Nov & Quantitative \\
\hline $62-9$ & 209 & 185 & M & Maturing & 220 & Dec & Quantitative \\
\hline $62-10$ & 214 & 221 & M & Maturing & 243 & Nov & Line \\
\hline \multicolumn{8}{|c|}{ Stn 66: Tsushima Current (40¹0' N, 13900' E), 11 July 1997} \\
\hline $66-1$ & 218 & 209 & $\mathrm{~F}$ & Immature & 222 & Dec & Line \\
\hline $66-8$ & 205 & 193 & M & Immature & 217 & Dec & Line \\
\hline $66-10$ & 198 & 173 & $\mathrm{M}$ & Maturing & 232 & Nov & Line \\
\hline
\end{tabular}

yama 1965). Statolith ageing revealed that the 2 groups attain a similar age $($ mean $=240 \mathrm{~d}$ ), yet show differential growth: ca. $230 \mathrm{~mm}$ mantle length (ML) at $265 \mathrm{~g}$ body weight (BW) in the Subarctic Group; ca. $210 \mathrm{~mm}$ ML at $190 \mathrm{~g} \mathrm{BW}$ in the Tsushima Group (Kidokoro \& Hiyama 1996). This suggests that, although they hatch during the same season, they form different groups that inhabit different regions during their northward migration. There are 2 possible explanations for these observations: either they are different groups originating from different spawning grounds, or they are the same hatchling group migrating on different routes subsequent to hatching.

Although ultrasonic telemetry has been used successfully with large neon flying squid Ommastrephes bartrami (Nakamura 1993), Todarodes pacificus is too small for such equipment. Special tools are therefore necessary.

Trace elements, especially strontium:calcium (Sr:Ca) ratios, in the calcified tissue of marine organisms have shown good correlation with ambient water temperature in corals (Smith et al. 1979), bivalves (Masuda 1976), and fishes (Gauldie et al. 1986, Radtke et al. 1990, Arai et al. 1996). Sr:Ca ratios have been used to examine migratory behavior in the ommastrephid squid Martialia hyadesi (Rodhouse et al. 1994), and ontogenetic variation was measured in 9 individuals of Ommastrephes bartrami (Yatsu et al. 1998), but Sr:Ca ratios have seldom been applied to squid migratory behavior in the field due to the difficulty in accounting for factors (e.g. ambient water temperature, ontogenetic conditions such as somatic growth, statolith growth) that might affect those ratios.

Sr concentrations (qualitatively equal to $\mathrm{Sr}$ : Ca ratios) in statoliths of Todarodes pacificus collected from the Sea of Japan are slightly higher in the Subarctic Group than in the Tsushima Group (Ikeda et al. 1998). An inverse relationship with ambient water temperature was also observed for Sr concentrations in statoliths of the Pacific jumbo octopus Octopus dofleini (Ikeda et al. 
1999). These observations suggest that statolith $\mathrm{Sr}: \mathrm{Ca}$ ratios in cephalopods may vary as a function of ambient water temperature. Microincrements in statoliths provide ageing information, since deposits occur on a daily basis in T. pacificus (Nakamura \& Sakurai 1991). Determining the migration of squid in nature is possible by combining ageing information with the ontogenetic change of statolith $\mathrm{Sr}$ :Ca ratios.

We report here 2 analyses of the variation of statolith Sr:Ca ratios in Todarodes pacificus caught in the Sea of Japan. The first reconstructs the migratory route of $T$. pacificus from their spawning grounds (Study 1); the second examines the migratory behavior of released and recovered sub-adult individuals (Study 2).

\section{MATERIALS AND METHODS}

Squid collection. To investigate the migratory routes (Study 1), 25 sub-adult Todarodes pacificus (10 males and 15 females) were collected from the central Sea of Japan by jigging during the summer of 1997 (Table 1, Fig. 1) and were immediately frozen whole. After thawing, morphometric measurements such as ML $(\mathrm{mm})$, BW $(\mathrm{g})$, sex, and weight $(\mathrm{g})$ of gonad were recorded. Maturity stages were determined following the method of Ikeda et al. $(1991 a, b)$. Statoliths were dissected and stored in $99.5 \%$ ethanol until further examination. Vertical profiles of water-column temperature at each collecting station were measured by STD (Alec Electronics Model AST-1000) (Table 2).

To correlate statolith $\mathrm{Sr}$ :Ca ratios with the migratory behavior of Todarodes pacificus (Study 2), we conducted tagging experiments in the summer of 1997. In total, 10354 squids were tagged and released from 7 sites between 24 June and 13 July 1997, and 91 squids were recovered (average recovery rate $=$ $0.88 \%$; average tagged duration $=38 \mathrm{~d}$ ). Of these, 12 squids were analyzed (Fig. 1B, Table 3).

Table 2. Temperature profiles $\left({ }^{\circ} \mathrm{C}\right)$ at sampling stations of Table 1

\begin{tabular}{|c|c|c|c|c|c|c|c|}
\hline \multirow{2}{*}{$\begin{array}{l}\text { Depth } \\
\text { (m) }\end{array}$} & & & & \multirow{2}{*}{$\begin{array}{c}\text { Stn } \\
11\end{array}$} & \multirow[b]{2}{*}{22} & \multirow[b]{2}{*}{62} & \multirow[b]{2}{*}{66} \\
\hline & 1 & 5 & 8 & & & & \\
\hline 0 & 21.0 & 19.4 & 17.1 & 17.5 & 15.4 & 21.4 & 22.8 \\
\hline 10 & 19.6 & 16.7 & 10.8 & 17.1 & 11.6 & 21.0 & 21.2 \\
\hline 20 & 17.1 & 12.3 & 8.2 & 11.5 & 5.8 & 19.6 & 20.8 \\
\hline 30 & 16.0 & 10.8 & 5.5 & 6.7 & 2.7 & 16.5 & 8.4 \\
\hline 50 & 13.2 & 8.9 & 2.1 & 3.6 & 1.8 & 13.5 & 16.0 \\
\hline 75 & 12.1 & 7.0 & 1.5 & 2.6 & 1.6 & 11.9 & 12.9 \\
\hline 100 & 11.5 & 5.7 & 1.3 & 2.2 & 1.4 & 10.9 & 11.6 \\
\hline 150 & - & 3.8 & 1.0 & 1.4 & 1.3 & 9.6 & 10.8 \\
\hline 200 & - & 2.5 & 0.9 & 1.2 & 1.1 & 6.5 & 8.9 \\
\hline 300 & - & 1.5 & 0.8 & 1.0 & 0.9 & 1.7 & 2.6 \\
\hline
\end{tabular}
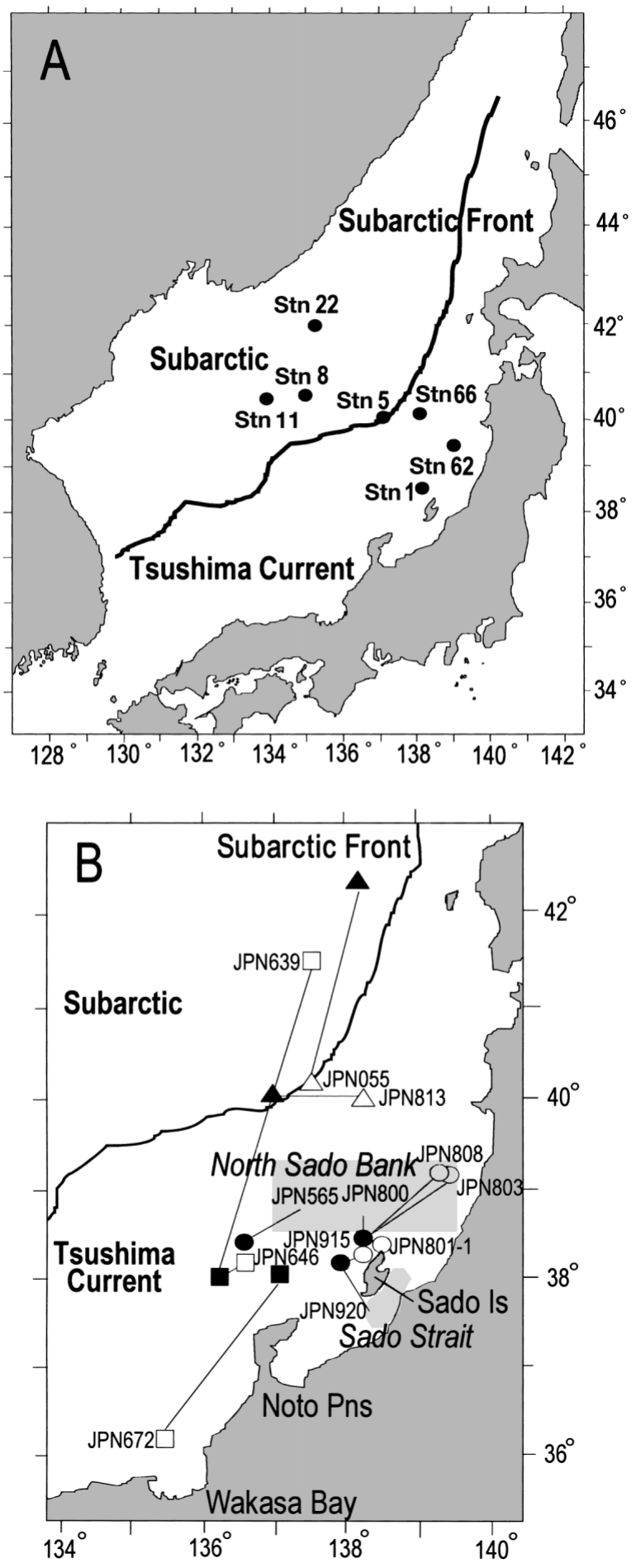

Fig. 1. Todarodes pacificus. Collection sites of Todarodes pacificus and oceanographic features in the Sea of Japan. (A) Sampling stations for Study 1. (B) Tagging and recovery sites for Study 2, showing tagging sites (black symbols) and recovery sites (open symbols) in offshore waters at Sado Island $(\bullet, 0)$ and Noto Peninsula $(\square, \square)$ in the Tsushima Current and the northern part of the Sea of Japan in the Subarctic $(\boldsymbol{\Lambda}$, $\Delta)$; identification numbers of individual squid are indicated at their respective recovery sites 
Table 3. Todarodes pacificus. Study 2 (correlation of statolith Sr:Ca ratios with migratory behavior) in 1997: release and recapture locations and body dimensions of tagged individuals. Maturity determined according to Ikeda et al. (1991a,b). ML: mantle length; F: female; M: male; nd: no data

\begin{tabular}{|c|c|c|c|c|c|c|c|c|c|c|c|}
\hline \multirow[t]{2}{*}{ Specimen } & \multicolumn{2}{|c|}{ Location } & \multicolumn{2}{|c|}{ Date } & \multirow{2}{*}{$\begin{array}{c}\text { Tagging } \\
\text { period } \\
\text { (d) }\end{array}$} & \multirow{2}{*}{$\begin{array}{c}\mathrm{ML} \\
(\mathrm{mm})\end{array}$} & \multirow{2}{*}{$\begin{array}{l}\text { Body } \\
\text { wt } \\
(g)\end{array}$} & \multirow[t]{2}{*}{ Sex } & \multirow[t]{2}{*}{ Maturity } & \multirow{2}{*}{$\begin{array}{c}\text { Age } \\
\text { (d) }\end{array}$} & \multirow{2}{*}{$\begin{array}{l}\text { Birth } \\
\text { month }\end{array}$} \\
\hline & Release & Recapt. & Release & Recapt & & & & & & & \\
\hline \multicolumn{12}{|c|}{ Sado/Tsushima Current } \\
\hline JPN800 & $38^{\circ} 42^{\prime} \mathrm{N}, 138^{\circ} 25^{\prime} \mathrm{E}$ & $39^{\circ} 05^{\prime} \mathrm{N}, 138^{\circ} 45^{\prime} \mathrm{E}$ & 24 Jun & $23 \mathrm{Jul}$ & 29 & 216 & 213 & $\mathrm{~F}$ & Maturing & nd & nd \\
\hline JPN801-1 & $38^{\circ} 42^{\prime} \mathrm{N}, 138^{\circ} 25^{\prime} \mathrm{E}$ & $38^{\circ} 34^{\prime} \mathrm{N}, 138^{\circ} 38^{\prime} \mathrm{E}$ & 24 Jun & 30 Jun & 6 & 218 & 191 & $\mathrm{~F}$ & Maturing & 243 & Oct \\
\hline JPN803 & $38^{\circ} 42^{\prime} \mathrm{N}, 138^{\circ} 25^{\prime} \mathrm{E}$ & $39^{\circ} 15^{\prime} \mathrm{N}, 139^{\circ} 30^{\prime} \mathrm{E}$ & 24 Jun & $10 \mathrm{Jul}$ & 16 & 190 & 122 & $\mathrm{M}$ & Immature & 231 & Nov \\
\hline JPN808 & $38^{\circ} 42^{\prime} \mathrm{N}, 138^{\circ} 25^{\prime} \mathrm{E}$ & $39^{\circ} 17^{\prime} \mathrm{N}, 139^{\circ} 24^{\prime} \mathrm{E}$ & 24 Jun & $6 \mathrm{Jul}$ & 12 & 227 & 173 & $\mathrm{M}$ & Mature & 312 & Aug \\
\hline JPN565 & $38^{\circ} 36^{\prime} \mathrm{N}, 136^{\circ} 54^{\prime} \mathrm{E}$ & $39^{\circ} 05^{\prime} \mathrm{N}, 138^{\circ} 45^{\prime} \mathrm{E}$ & $5 \mathrm{Jul}$ & $22 \mathrm{Jul}$ & 17 & 210 & nd & nd & nd & 234 & Nov \\
\hline JPN915 & $38^{\circ} 10^{\prime} \mathrm{N}, 138^{\circ} 00^{\prime} \mathrm{E}$ & $38^{\circ} 27^{\prime} \mathrm{N}, 138^{\circ} 20^{\prime} \mathrm{E}$ & $13 \mathrm{Jul}$ & $18 \mathrm{Jul}$ & 5 & 231 & 268 & $\mathrm{~F}$ & Immature & 268 & Oct \\
\hline JPN920 & $38^{\circ} 10^{\prime} \mathrm{N}, 138^{\circ} 00^{\prime} \mathrm{E}$ & $37^{\circ} 50^{\prime} \mathrm{N}, 138^{\circ} 40^{\prime} \mathrm{E}$ & $13 \mathrm{Jul}$ & $29 \mathrm{Jul}$ & 16 & 198 & 178 & $\mathrm{~F}$ & Immature & 236 & Dec \\
\hline \multicolumn{12}{|c|}{ Noto-Wakasa Bay/Tsushima Current } \\
\hline JPN672 & $38^{\circ} 00^{\prime} \mathrm{N}, 137^{\circ} 00^{\prime} \mathrm{E}$ & $36^{\circ} 17^{\prime} \mathrm{N}, 135^{\circ} 42^{\prime} \mathrm{E}$ & 21 May & Aug & $>40$ & 213 & 146 & $\mathrm{~F}$ & Mature & 270 & Nov \\
\hline \multicolumn{12}{|c|}{ Noto-North Japan Sea/Tsushima Current } \\
\hline JPN639 & $38^{\circ} 00^{\prime} \mathrm{N}, 136^{\circ} 20^{\prime} \mathrm{E}$ & $41^{\circ} 49^{\prime} \mathrm{N}, 137^{\circ} 47^{\prime} \mathrm{E}$ & $1 \mathrm{Jul}$ & 5 Aug & 35 & 259 & 337 & M & Maturing & 257 & Nov \\
\hline $\begin{array}{l}\text { Noto/Tsus } \\
\text { JPN646 }\end{array}$ & $\begin{array}{l}\text { shima Current } \\
38^{\circ} 00^{\prime} \mathrm{N}, 136^{\circ} 20^{\prime} \mathrm{E}\end{array}$ & $38^{\circ} 21^{\prime} \mathrm{N}, 136^{\circ} 56^{\prime} \mathrm{E}$ & $1 \mathrm{Jul}$ & $21 \mathrm{Jul}$ & 13 & 187 & 128 & $\mathrm{~F}$ & Immature & 214 & Dec \\
\hline \multicolumn{12}{|c|}{ North Japan Sea/Subarctic-Tsushima Current } \\
\hline \multicolumn{12}{|c|}{ North Japan Sea/Subarctic } \\
\hline JPN055 & $42^{\circ} 29^{\prime} \mathrm{N}, 138^{\circ} 19^{\prime} \mathrm{E}$ & $40^{\circ} 09^{\prime} \mathrm{N}, 137^{\circ} 58^{\prime} \mathrm{E}$ & 26 Jun & $21 \mathrm{Jul}$ & 25 & 242 & 331 & M & Mature & 279 & Oct \\
\hline
\end{tabular}

Statolith preparation. One of each pair of statoliths was used for Sr and Ca analyses and age determination. Stored statoliths were cleaned several times with $99.5 \%$ ethanol, dried, and mounted in a cylindrical silicone stub filled with polyester resin. After hardening, the polyester block was polished from the anterior side. Terminology for statolith dimensions follows that of Clarke (1978). The dorsal dome and lateral dome of the mounted statoliths, which faced the bottom of the polyester block, were ground with fine-graded carbide $(240,2000,3000,4000$ grade) waterproof paper, until the nucleus was exposed. Ground statoliths were polished with $3 \mu \mathrm{m}$ followed by $1 \mu \mathrm{m}$ diamond paste, and then coated with carbon for electron microprobe analyses.

$\mathrm{Sr}$ and $\mathrm{Ca}$ measurements and microincrement counts. A wavelength-dispersive spectrometer (Shimadzu EPMA-C1 Model 40) was used for electron microprobe analyses.

For the quantitative analysis (point-analysis) in Study 1, we measured X-ray intensities of Sr and Ca at 15 points from the nucleus to the edge of the dorsal dome. Since we observed that the main growth axis of Todarodes pacificus statolith changed ontogenetically, we selected 2 lines for measurement based on these growth axes in the statolith: the first axis was in the direction of the lateral dome, the second from the end of the first line to the edge of the dorsal dome (Fig. 2). Statoliths of 3 squids from the Subarctic, 3 from the Tsushima Current, and 2 from the Subarctic Front were measured under the following experimental conditions: an acceleration voltage of $15 \mathrm{kV}$, a beam current of $100 \mathrm{nA}$, and a $5 \mu \mathrm{m}$ diameter focused beam with a counting time of $40 \mathrm{~s}$ for $\mathrm{Sr}$ and $5 \mathrm{~s}$ for $\mathrm{Ca} . \mathrm{CaSiO}_{3}$ and $\mathrm{SrTiO}_{3}$ were used as standards for Ca and Sr. After electron microprobe analysis, the number of microincrements was counted with light microscopy from the nucleus to the dorsal dome (i.e. throughout the statolith). Microincrements were counted 4 times for each specimen, and to exclude erratic counts the middle 2 counts were averaged (i.e. median) to determine the age, in days, of the squid.

The variation in $\mathrm{Sr}$ : Ca ratios in statoliths of squid from different locations was also measured by line analysis, which measures a string of trace elemental peaks along a line of continuous beam spots. For this purpose, ground and polished statoliths from 8 squid from the Subarctic and 9 from the Tsushima Current were analyzed. Since only a single line measurement is applicable to 1 specimen in line analysis, X-ray intensities of $\mathrm{Sr}$ and Ca were continuously measured in a single direction from the nucleus to the edge of the dorsal dome (Fig. 2). The measurement conditions were: acceleration voltage of $15 \mathrm{kV}$, beam current of $100 \mathrm{nA}$, and $5 \mu \mathrm{m}$ diameter focused beam with a counting time of 5 and $0.1 \mathrm{~s}$ for $\mathrm{Sr}$ and $\mathrm{Ca}$, respectively. For each specimen, quantitative analysis was also performed at several points, from which we calculated concentrations of Sr and Ca measured by line analysis. 
In contrast to the quantitative analysis, in the line analysis each beam spot did not align with the microincrements in the examined statolith, since the traces of the beam spots were visible as a continuous line (Fig. 2C). Therefore, variation in the $\mathrm{Sr}$ :Ca ratios was correlated with days after hatching from the individual age and number of the beam spot.

For Study 2, statoliths of 12 tagged Todarodes pacificus (4 males, 7 females and 1 of unknown sex) were measured by line analysis. For this purpose, the $\mathrm{Sr}$ and $\mathrm{Ca}$ of an area of the dorsal dome (including the section that had grown during the time the squid were tagged) were measured at the following settings: acceleration voltage of $15 \mathrm{kV}$, beam current of $50 \mathrm{nA}$, and $1 \mu \mathrm{m}$ diameter focused beam with a counting time of 5 and $0.1 \mathrm{~s}$ for $\mathrm{Sr}$ and $\mathrm{Ca}$, respectively. Calculations of $\mathrm{Sr}$ and $\mathrm{Ca}$ concentrations were performed in the same manner as for Study 1. The timing of the variations in the $\mathrm{Sr}: \mathrm{Ca}$ ratios in the examined individuals was estimated as follows: because microincrement widths of $T$. pacificus' statoliths range between ca. 1.2 and $2.5 \mu \mathrm{m}$ (data not shown), microincrement width in the statoliths of the examined specimens was assumed to be $2 \mu \mathrm{m}$. The edge of the examined statolith was taken as the recovery date. Therefore, variation in Sr:Ca ratios was calculated based on the time from the date of recovery to the date of release, with the assumption that statolith growth in a single day was $2 \mu \mathrm{m}$.

\section{RESULTS}

The age of the captured Todarodes pacificus was 191 to $262 \mathrm{~d}, \mathrm{ML}=190$ to $218 \mathrm{~mm}$ (Study 1, Table 1), and that of tagged specimens was 214 to $312 \mathrm{~d}, \mathrm{ML}=187$ to $259 \mathrm{~mm}$ on recovery (Study 2, Table 3). The body size and age of these specimens were similar to those of $T$. pacificus caught along the Subarctic Front during the summer of 1995 (Kidokoro \& Hiyama 1996).

\section{Study 1}

Fig. 2 shows Todarodes pacificus statoliths measured by quantitative analysis with a spectrometer. Transparent and opaque regions were observed in the statoliths (Fig. 2A). Sr and Ca were measured along 2 growth axes of the statoliths. Ontogenetic variations in the quantitative statolith $\mathrm{Sr}$ :Ca ratios of $T$. pacificus caught in the Subarctic, the Tsushima Current, and the Subarctic Front are shown in Fig. 3. Sr:Ca ratios were high (range 0.019 to 0.021 , mean $=0.021$ ) near the nucleus of statolith (i.e. at hatching) and decreased to about 0.015 at $10 \mathrm{~d}$ of age in both the Subarctic and the Tsushima Groups. A wide range in $\mathrm{Sr}$ :Ca ratios (0.017 to 0.024$)$ occurred from 70 to $140 \mathrm{~d}$ of age, hereafter referred to as 'young' stage (squid of 20 to $150 \mathrm{~mm}$ ML that are pre-recruited for fisheries, as defined by Kidokoro \&
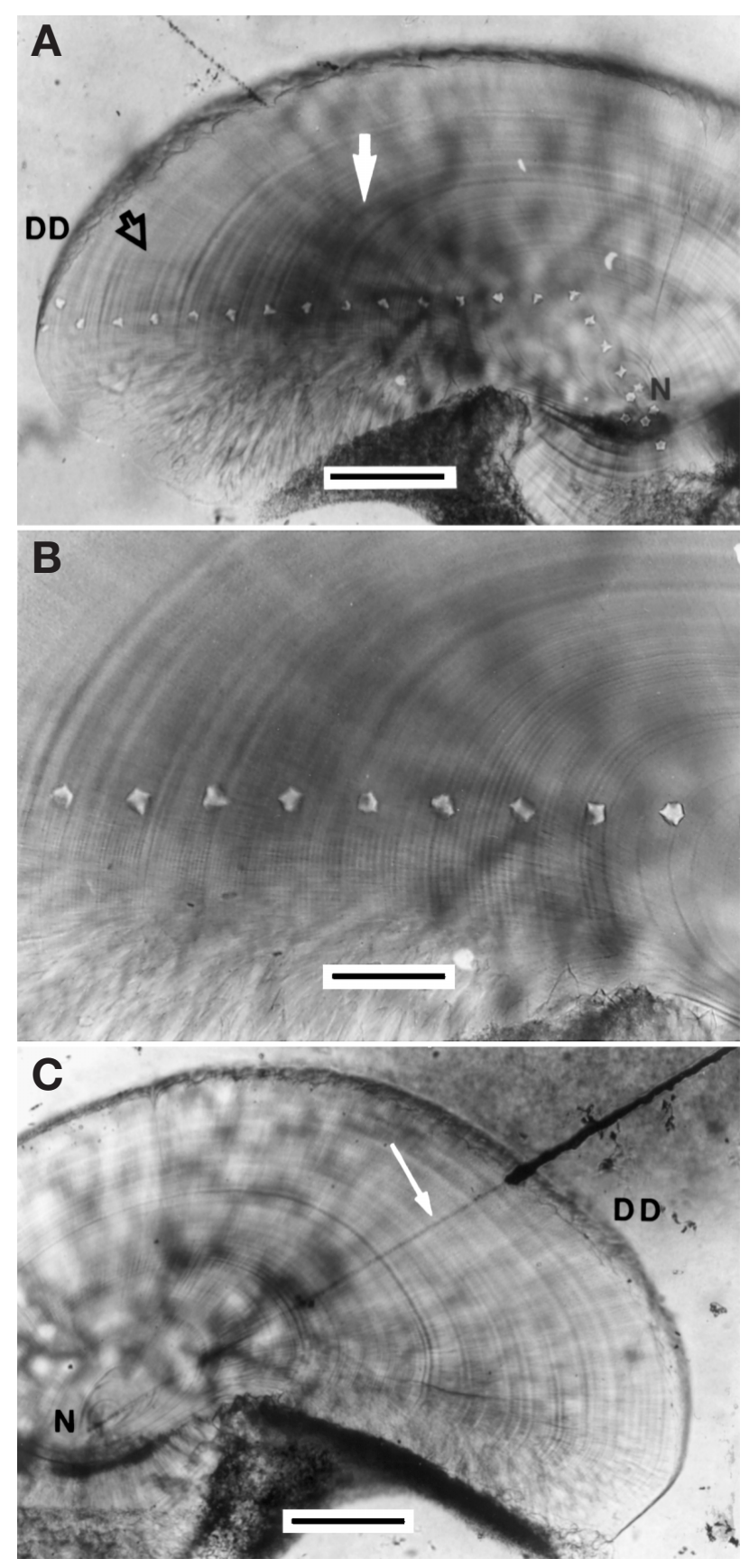

Fig. 2. Todarodes pacificus. Light micrograph of a statolith. (A) Female (mantle length, ML $=212 \mathrm{~mm}$ ) measured by quantitative spectrometry ( $5 \mu \mathrm{m}$ diam.) analysis; note ontogenetical change in growth axis of statolith, and transparent (open arrow) and opaque (white arrow) areas. (B) Detail of (A). (C) Female $(\mathrm{ML}=210 \mathrm{~mm})$ measured by spectrometric $(5 \mu \mathrm{m}$ diam.) line analysis; note beam spots in continuous line (arrow). DD: dorsal dome; N: nucleus. Scale bars $=100 \mu \mathrm{m}$ for (A) and (C), $50 \mu \mathrm{m}$ for (B) 


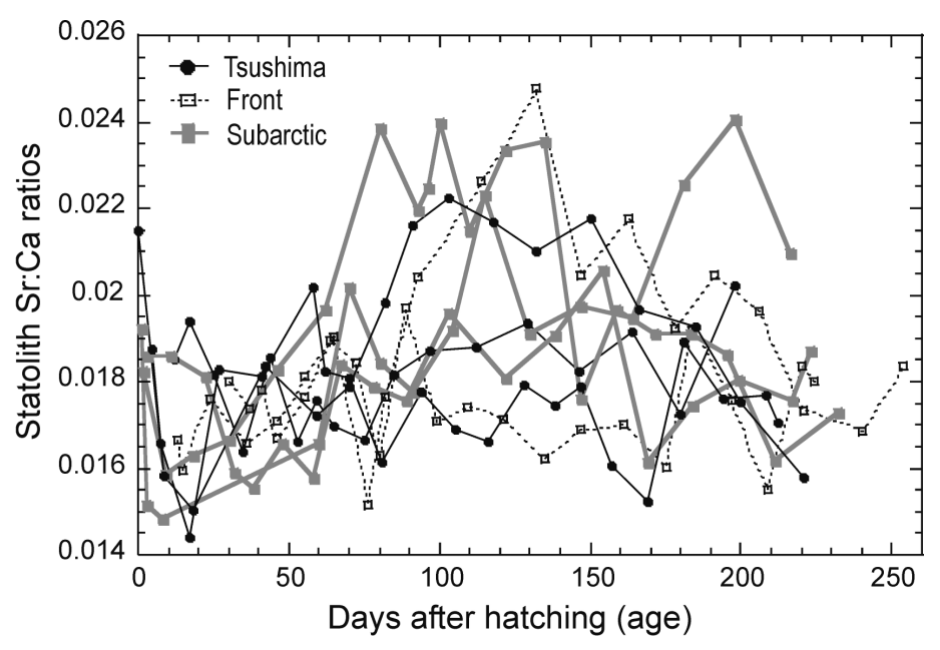

Fig. 3. Todarodes pacificus. Ontogenetic variation in Sr:Ca ratios in statoliths of 8 squids collected from the Subarctic $(n=3)$, Tsushima Current $(n=3)$ and Subarctic Front $(n=2)$. Sr and Ca were measured by quantitative spectrometric analysis from nucleus to dorsal dome edge

Wada 1997). Sr:Ca ratios at the edge of the statolith (corresponding to the period between 220 and $250 \mathrm{~d}$ of age, i.e. the period during which the squid inhabit in the Subarctic, the Tsushima Current or the Subarctic Front) were similar in individuals examined from all 3 groups (ca. 0.017). The Sr:Ca ratios of these groups did not seem to vary particularly in pattern (Fig. 3).

Fig. 4 shows the ontogenetic variation in statolith Sr:Ca ratios based on line analysis for 17 squids from the Subarctic and the Tsushima Current. Tendencies similar to those illustrated in Fig. 3 were observed in the very young and sub-adult stages (Fig. 4). Of 17 individuals, 11 had Sr:Ca ratios above 0.019 (range 0.019 to 0.023 , mean $=0.020$ ) at hatching; these ratios decreased to about 0.019 at $10 \mathrm{~d}$ of age, and to about 0.018 between 200 and $250 \mathrm{~d}$ of age (sub-adult stage) (Fig. 4). However, there was a difference between the 2 geographical groups for the 40 to $150 \mathrm{~d}$ old ('young' stage) individuals. This difference is clear from Fig. 5, which shows running 5-point means for the $\mathrm{Sr}$ :Ca ratios in Fig. 4. In the Tsushima Group, Sr:Ca ratios increased in $40 \mathrm{~d}$ old specimens and remained high, at around 0.021, until $150 \mathrm{~d}$ of age, after which they decreased. This tendency was practically identical for 9 individuals at the 'young' stage in the Tsushima Group (Fig. 5, see also Fig. 4). Conversely, large fluctuations in the $\mathrm{Sr}$ :Ca ratio were observed at various times between 40 and $150 \mathrm{~d}$ old individuals in the Subarctic Group. Thus, the pattern of Sr:Ca ratio variation was not identical for the 8 individuals at the 'young' stage in the Subarctic Group (Fig. 5; see also Fig. 4). These tendencies were reflected in the mean statolith Sr:Ca ratios at intervals of $10 \mathrm{~d}$ for individuals in the Subarctic and Tsushima Groups
(Fig. 6). In the Tsushima Group, Sr:Ca ratios increased in $40 \mathrm{~d}$ old squid, remaining high up to $150 \mathrm{~d}$ of age, when they began to decrease. However no similar pattern was observed in the Subarctic Group, in which the Sr:Ca ratios for the 'young' stage were relatively low, with large fluctuations among individuals at between 40 and $150 \mathrm{~d}$ of age (Fig. 6).

\section{Study 2}

Fig. 7 shows the variation in $\mathrm{Sr}$ :Ca ratios of statoliths of tagged Todarodes pacificus that were released and recovered in northern offshore waters of Sado Island, offshore waters of the Noto Peninsula in the Tsushima Current, and waters of the northern portion of the Sea of Japan in the Subarctic in summer 1997 (see also Fig. 1B, Table 3). Statolith Sr:Ca ratios in these specimens were higher than those shown by the line analysis for statoliths
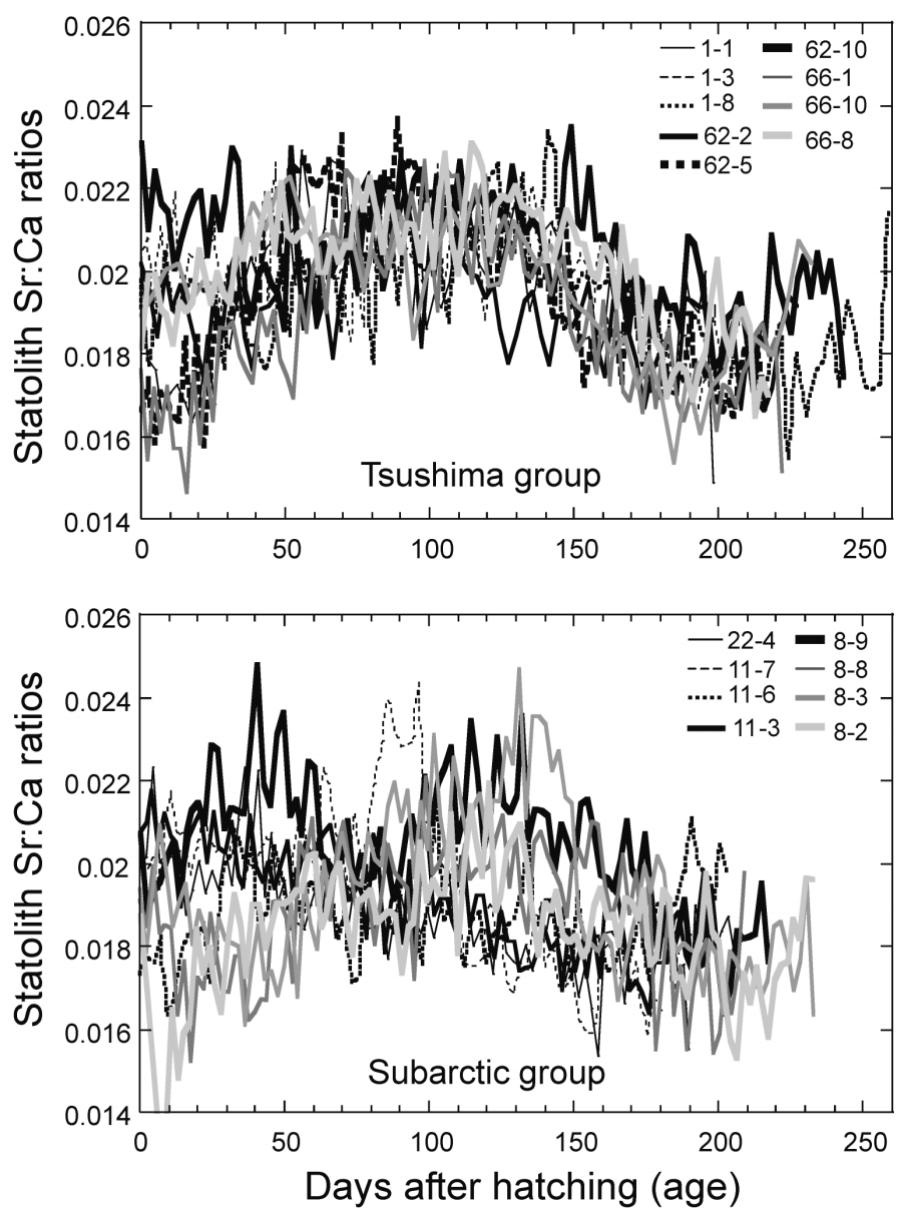

Fig. 4. Todarodes pacificus. Ontogenetic variation in Sr:Ca ratios in statoliths of 17 squids collected from the Subarctic (Subarctic Group, $\mathrm{n}=8$ ) and the Tsushima Current (Tsushima Group, $\mathrm{n}=9$ ). $\mathrm{Sr}$ and $\mathrm{Ca}$ were measured by spectrometric ( $5 \mu \mathrm{m}$ diameter) line analysis from nucleus to dorsal dome edge. Squid identification numbers as in Table 1 

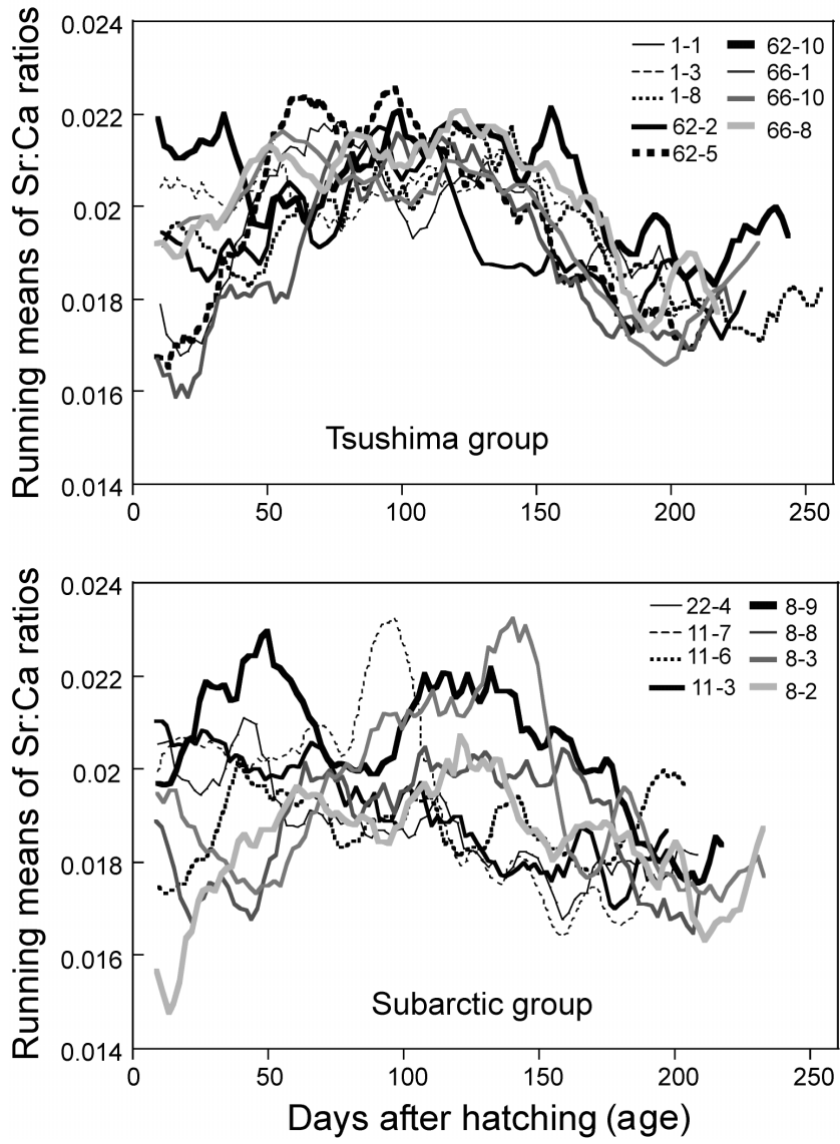

Fig. 5. Todarodes pacificus. Running means of ontogenetic variation in Sr:Ca ratios in statoliths of 17 squids collected from the Subarctic (Subarctic Group, $\mathrm{n}=8$ ) and the Tsushima Current (Tsushima Group, $\mathrm{n}=9$ ). Squid identification numbers as in Table 1

of the Subarctic Group and Tsushima Group. This could be related to the smaller diameter $(1 \mu \mathrm{m})$ of the spectrometer used, which increased the beam power density compared to that achieved with a larger beam $(5 \mu \mathrm{m})$. This tendency was also observed for 3 specimens from the Subarctic and the Tsushima Current, which were preliminarily measured by a $2 \mu \mathrm{m}$ beam of the spectrometer (line analysis; data not shown). No remarkable difference was found in the statolith $\mathrm{Sr}$ :Ca ratios of $T$. pacificus recovered in these areas (0.040 to 0.042). Small fluctuations in the $\mathrm{Sr} / \mathrm{Ca}$ ratios roughly corresponded to a daily cycle during the tagged period. This variation was not a statistical error in the X-ray, as indicated by the following equation (Soejima 1993):

$$
\begin{aligned}
& N_{A}-\sqrt[3]{N_{A}}>N_{B}+\sqrt[3]{N_{B}}(99.7 \%) \\
& N_{A}-\sqrt[2]{N_{A}}>N_{B}+\sqrt[2]{N_{B}}(95.4 \%) \\
& N_{A}-\sqrt{N_{A}}>N_{B}+\sqrt{N_{B}}(68.3 \%)
\end{aligned}
$$

where $N_{A}$ and $N_{B}$ are the maximum and minimum counts for $\mathrm{Sr}$ and Ca detected in a peak, respectively, and the percentages in parentheses are their probability. Variations in Ca were not probable, whereas variations in $\mathrm{Sr}$ were probable $(95.4 \%$ probability of small fluctuations).

Beside small fluctuations in the $\mathrm{Sr}$ :Ca ratios, seasonal variation was observed in the statolith $\mathrm{Sr}$ :Ca ratios of a tagged specimen, JPN800, that was released and recovered off Sado Island (Fig. 7). Based on the data for release and recovery sites, this individual seemed to stay at the release site (Fig. 1B, Table 3). This was also supported by the data for other individuals (not shown) that were concurrently released off Sado Island (Kidokoro 1999). Statolith Sr:Ca ratios in Squid JPN800 were low at the end of June, increased substantially in early July, and decreased markedly toward the end of July. This was a typical and probable $(99.7 \%)$ fluctuation for $\mathrm{Sr}$ :Ca ratios. Similar fluctuations were observed for Squids JPN803 and JPN565 that also remained at the North Sado Bank (Figs. 1B \& 7, Table 3).

Fig. 8 shows 5-point running means of $\mathrm{Sr}$ :Ca ratios for tagged individuals. The seasonal variation in the $\mathrm{Sr}: \mathrm{Ca}$ ratios of statoliths is clear for JPN800, JPN803 and JPN565 (although the Sr:Ca ratio in JPN565 was relatively low), whereas no similar pattern was observed for JPN639 and JPN055, which remained in offshore waters of the Noto Peninsula and waters of the northern portion of the Sea of Japan, respectively, between the end of June and the end of July (Fig. 8, Table 3).

\section{DISCUSSION}

\section{Early life history and migration}

Based on the buoyancy characteristics of Todarodes pacificus egg masses, it is possible that spawned eggs

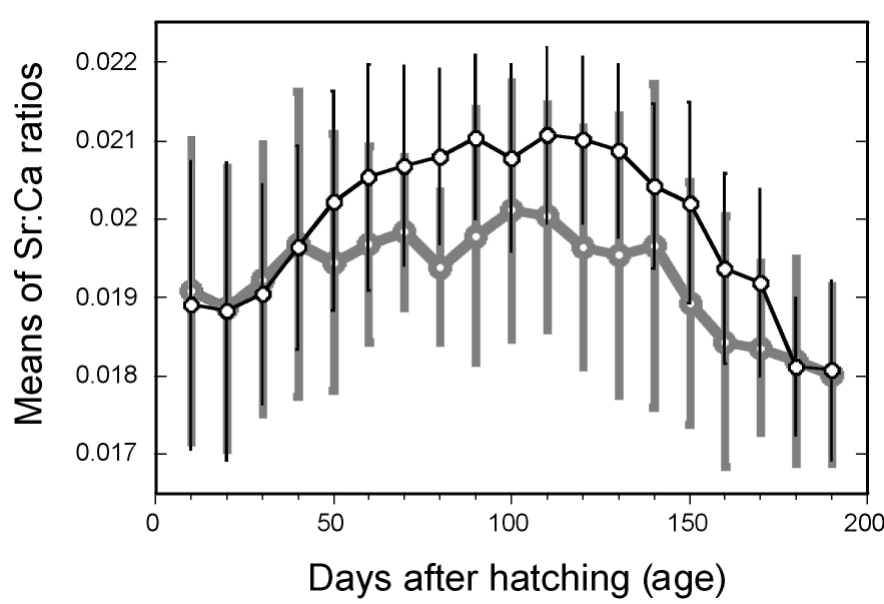

Fig. 6. Todarodes pacificus. Mean $( \pm \mathrm{SD})$ statolith $\mathrm{Sr}$ :Ca ratios in the Subarctic ( $\mathrm{n}=8$, gray circle) and Tsushima $(\mathrm{n}=9$, black circle) groups at $10 \mathrm{~d}$ intervals 

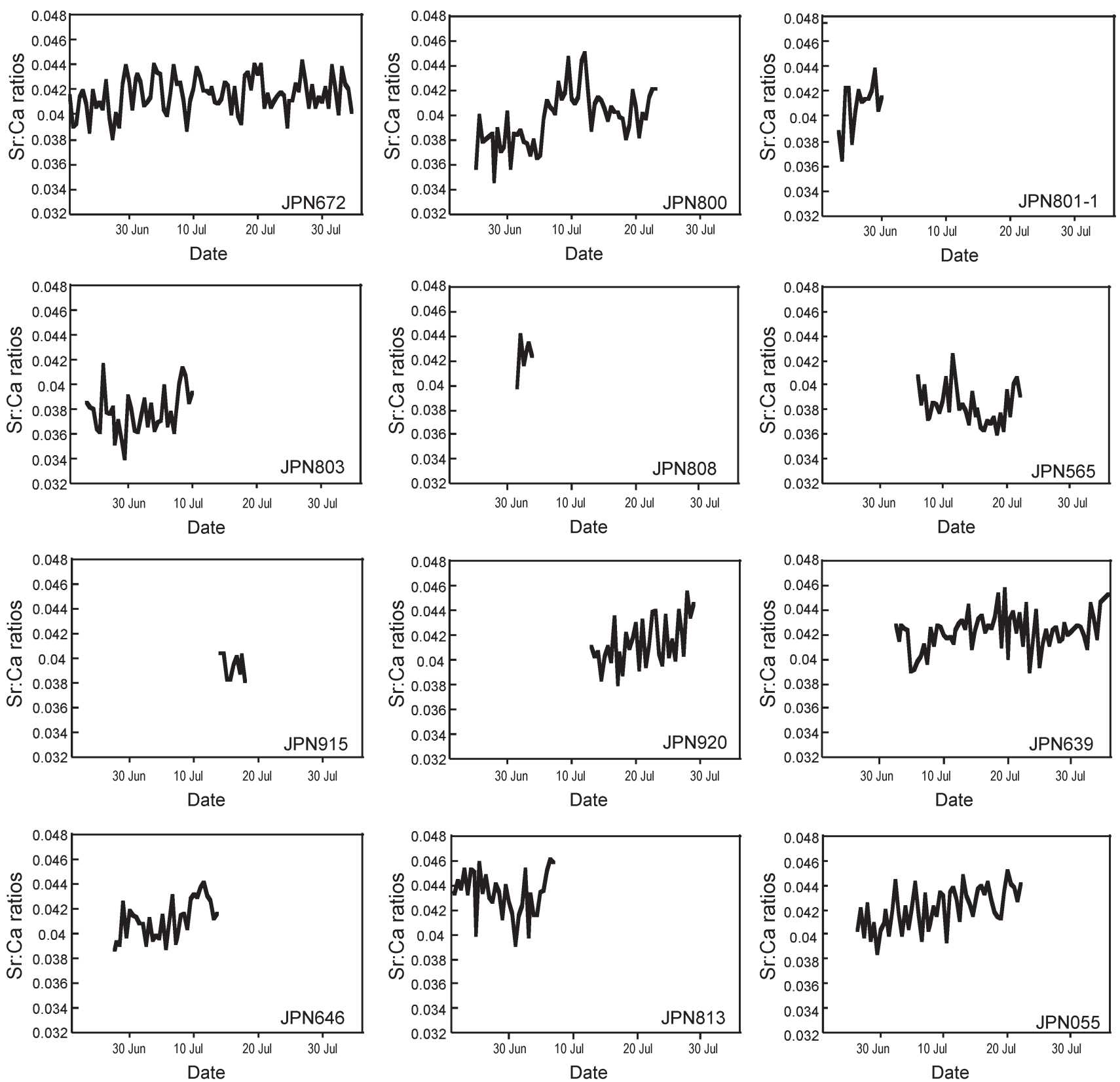

Fig. 7. Todarodes pacificus. Variation in Sr:Ca ratios of squids tagged and recovered in the Subarctic and in the Tsushima Current in 1997. Sr and Ca measured by spectrometric (1 $\mu \mathrm{m}$ diameter) line analysis of the part grown during period squid were tagged.

Squid identification numbers as in Fig. 1B \& Table 3

could be suspended along thermoclines until hatching, and that the hatched juveniles would then move to surface waters (Sakurai \& Ikeda 1994, Bower \& Sakurai 1996). The high statolith Sr:Ca ratios at hatching and the rapid decrease in these ratios during the subsequent 10 d (Figs. 3 \& 4) support this hypothesis.

Because Todarodes pacificus hatchlings are poor swimmers, they are transported by the Tsushima Current toward inshore and offshore waters in the Sea of
Japan. T. pacificus paralarvae are caught in the Sea of Japan waters both offshore (Murata 1983) and inshore (Kidokoro \& Wada 1997), indicating that T. pacificus paralarvae are transported to offshore and inshore waters under different thermal conditions. Various ranges in temperature in the nursery grounds for $T$. pacificus paralarvae would be reflected in a large variation in statolith $\mathrm{Sr}$ :Ca ratios in 70 to $140 \mathrm{~d}$ old specimens (see Fig. 3). A decrease in the Sr:Ca ratios after 


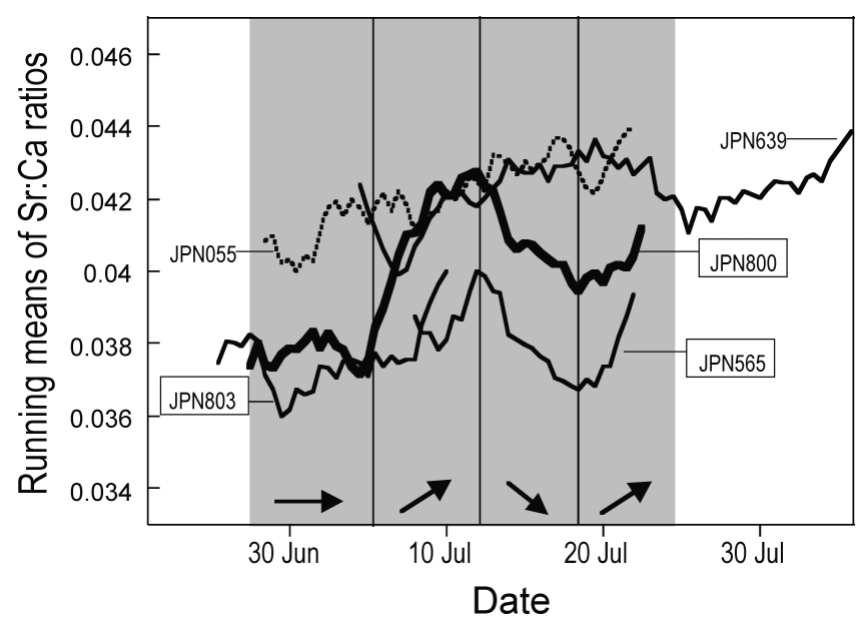

Fig. 8. Todarodes pacificus. Ontogenetic variation in running means ( $\mathrm{RM}, \mathrm{n}=5$ ) of $\mathrm{Sr}$ :Ca ratios in statolith of tagged squids (JPN800, JPN803, JPN565 from offshore waters of Sado Island, JPN639 from offshore waters of the Noto Peninsula, and JPN055 from offshore waters of the northern part of the Sea of Japan). Arrows indicate trend of Sr:Ca ratios for JPN800, JPN803 and JPN565, all of which displayed the same pattern. Squid identification as in Fig. 1B and Table 3

this age could indicate that young $T$. pacificus develop into active swimmers in their nursery grounds before moving to feeding grounds in either the Subarctic or the Tsushima Current.

However, differences in spawning grounds as well as differences in transport route between the Tsushima and the Subarctic Groups must also be considered, since Sr:Ca ratio patterns vary at the 'young' stage between these 2 groups. Although the Sr:Ca ratio patterns were almost identical in 'young' individuals of the Tsushima Group, in the Subarctic Group the ratios varied between individuals (see Figs. 4 to 6). Since $\mathrm{Sr}$ :Ca ratios vary as a function of environmental conditions, these features suggest a difference in both spawning ground and transport route between these 2 groups (the members of which all hatched between October and December 1996) (Table 1). This hatching period has traditionally been associated with an autumn population (Shojima \& Hotta 1972, Kasahara 1978, Okutani 1983, Kidokoro \& Hiyama 1996). The spawning ground of the autumn population has been considered to extend from the SW part of the Sea of Japan to inshore waters of NW and western Kyushu and the northern part of the East China Sea (Kasahara \& Ito 1972, Shojima \& Hotta 1972). As these areas are strongly affected by the Tsushima Current, the transport route of Todarodes pacificus paralarvae from this spawning ground to the Subarctic Front in the Sea of Japan was hypothesized to be along the Tsushima Current (Kasahara 1978). However, since there are 3 branches of the Tsushima Current, paralarvae would be transported along different routes by different branches of the current if their spawning grounds differed horizontally. This has been illustrated by Kasahara \& Ito (1972). Because of an abundance of paralarvae, inshore waters of the southern Korea Peninsula are also presumed to constitute a spawning ground for T. pacificus (Yamamoto 1946, Hamabe \& Shimizu 1966). Thus it appears, based on previously published work (Yamamoto 1946, Hamabe \& Shimizu 1966, Kasahara \& Ito 1972), that a broad horizontal range of spawning grounds for T. pacificus exists near the source of the Tsushima Current.

Based on its Sr:Ca ratios, the Tsushima Group appears to have been spawned at a site affected by the first branch of the Tsushima Current, and to have been transported to warm-water regions partly by coastal waters. This route is thermally stable, and this is reflected in the similar patterns of the Sr:Ca ratios of this group. The variations in the Sr:Ca ratios of the 'young' stage of the Subarctic Group suggest that these individuals spawned nearer the western side of the presumed spawning area. This area is strongly affected by the third branch of the Tsushima Current, and thus the paralarvae would be transported by this branch of the current into the Subarctic Front. This route is thermally unstable, and this is reflected in the variation in the Sr:Ca ratios of the 'young' stage in the Subarctic Group. After the seasonal temperature increase, this group migrated across the Subarctic Front to the Subarctic $i$ this is supported by the observations of Kasahara \& Ito (1968), who reported that Subarctic Group squid migrate to a cold-water region, whereas Tsushima Group squid migrate to a warm-water region, during their southward migration (Kasahara \& Ito 1968).

According to the inverse relationship between water temperature and statolith $\mathrm{Sr}$ :Ca ratios reported for Todarodes pacificus in nature (Ikeda et al. 1998), the high Sr:Ca ratios in the Tsushima Group (warm-water region) seem contradictory (Fig. 4), whereas the high Sr:Ca ratios observed for some of the Subarctic Group (i.e. Individuals 8-9, 11-6, 8-8: Fig. 4) corresponds to such an inverse relationship. However, since, as mentioned, the Subarctic Group presumably migrate along a thermally unstable route, they would experience a wider range of ambient temperatures than the Tsushima Group, and this could strongly affect the pattern of statolith $\mathrm{Sr}: \mathrm{Ca}$ ratios in the Subarctic Group. To determine this, the relationship between statolith Sr:Ca ratios and water temperature should be examined experimentally. Also, determination of the $\mathrm{Sr}: \mathrm{Ca}$ ratios of the water-masses of $T$. pacificus' habitat (which requires a different method of measurement than electron-probe microanalysis and thus was not measured in the present study) would be helpful in reconstructing the migratory route(s) of this species. 


\section{Information derived from statoliths of tagged squid}

Small fluctuations in the $\mathrm{Sr}$ :Ca ratios roughly corresponding to the daily cycle were observed in the tagged individuals regardless of tagging duration. It is possible that diel vertical migrations between $200 \mathrm{~m}$ and the surface layer (Hamabe 1964) could explain these fluctuations, since this presumably exposes individuals to a wide temperature change during each $24 \mathrm{~h}$ period. Yet there was no noticeable difference in the fluctuations in the Sr:Ca ratios between tagged individuals caught in cold waters with a vertically large temperature gradient and those caught in warm waters with a vertically small temperature gradient (Table 2).

It is more likely that daily fluctuations in $\mathrm{Sr}$ :Ca ratios are due to endogenous factors. Similar small fluctuations in statolith $\mathrm{Sr}$ :Ca ratios were observed in captive Todarodes pacificus reared at a constant temperature for $60 \mathrm{~d}$ (Ikeda et al. 2002). Furthermore, daily cycles in $\mathrm{Ca}^{2+}$ and $\mathrm{Sr}^{2+}$ concentrations in the statocyst endolymph of the cuttlefish Sepia officinalis and the long-finned squid Loligo vulgaris has been observed (Bettencourt \& Guerra 2000).

The tagged individuals JPN800, JPN803 and JPN565 remained on the North Sado Bank (offshore waters of Sado Island) during the whole tagging period. We assume that the variation of their $\mathrm{Sr}$ :Ca ratios reflects seasonal changes in their environment. In early July 1997, a cold-water layer $\left(5\right.$ to $10^{\circ} \mathrm{C}$ at $100 \mathrm{~m}, 2$ to $5^{\circ} \mathrm{C}$ at $200 \mathrm{~m}$ ) developed on the North Sado Bank. This layer had moved northward by late July 1997. The inverse relationship between statolith $\mathrm{Sr}$ concentration and ambient temperature in Todarodes pacificus (Ikeda et al. 1998), and the substantial increase, and subsequent decrease, in the statolith Sr:Ca ratios of JPN800, JPN803 and JPN565 between early and mid-July reflect the formation and movement of this cold-water layer. This pattern was not observed for tagged specimens JPN639 and JPN055, which moved to waters away from the North Sado Bank between early July and early August. These results support the concept that $\mathrm{Sr}$ :Ca ratios in statoliths act as a monitoring system for squid migratory behavior.

\section{Conclusions}

Characteristic patterns of $\mathrm{Sr}: \mathrm{Ca}$ ratios in Todarodes pacificus statoliths suggest that statoliths can be used as a monitoring system for migratory behavior. They record the long-term migratory history (Study 1) and seasonal environmental variation in the habitats (Study 2), presumed endogenous rhythms, and/or vertical movements of the squid (see daily cycle of $\mathrm{Sr} / \mathrm{Ca}$ fluctuation recorded in Study 2). However, the mechanisms of Sr incorporation into the statoliths must be determined, and their relationship to ambient water temperature and other environmental factors, as well as to exogenous factors be clarified to enable the information contained in the statoliths to be interpreted more precisely.

Acknowledgements. We express our sincere thanks to the captain and crews of the training vessels 'Ootori-maru' and 'Chokai-maru' for squid collection, and members of the regional fisheries experimental stations involved in the tagging project. Niigata Prefectural Fisheries and the Marine Research Institute are acknowledged for providing temperature data around Sado Island. We are grateful to the Institute of Frontier Medical Science of Kyoto University for their permission to use a wavelength dispersive spectrometer. Sincere thanks are also expressed to A. Yatsu and N. Mochioka, who kindly advised us regarding the conditions of spectrometer measurement. We acknowledge T. Ikeda and M. Yamamoto for their kind instructions on operating the spectrometer, and J. Arakawa, Y. Nagata, T. Ohta and J. Okazaki for helpful discussion and cooperation. Special thanks to J. Hunt for critically reading the draft manuscript. Most of the study done was carried out while Y. I. was at the Fisheries Environmental Oceanography Laboratory, Kyoto University. The members of that Laboratory are gratefully acknowledged for their informative discussion and encouragement. This study was supported in part by a Grant-in-Aid for Encouragement of Young Scientists of the Ministry of Education, Science, Sports and Culture of Japan.

\section{LITERATURE CITED}

Arai N, Sakamoto W, Maeda K (1996) Correlation between ambient seawater temperature and strontium-calcium concentration ratios in otoliths of red sea bream Pagrus major. Fish Sci 62:652-653

Bettencourt V, Guerra A (2000) Growth increments and biomineralization process incephalopod statoliths. J Exp Mar Biol Ecol 248:191-205

Bower JR, Sakurai Y (1996) Laboratory observations on Todarodes pacificus (Cephalopoda: Ommastrephidae) egg mass. Am Malacol Bull 13:65-71

Clarke MR (1978) The cephalopod statolith - an introduction to its form. J Mar Biol Assoc UK 58:701-712

Gauldie RW, Fournier DA, Dunlop DE (1986) Atomic emission and proton microprobe studies of the ion content of otoliths of chinook salmon aimed at recovering the temperature life history of individuals. Comp Biochem Physiol A 84:607-615

Hamabe M (1964) Study on the migration of squid (Ommastrephes sloani pacificus Steenstrup) with reference to the age of the moon. Nippon Suisan Gakkaishi 30:209-215

Hamabe M, Shimizu T (1966) Ecological studies on the common squid, Todarodes pacificus Steenstrup, mainly in the southwestern waters of the Japan Sea. Bull Jpn Sea Reg Fish Res Lab 16:13-55

Ikeda Y, Sakurai Y, Shimazaki K (1991a) Development of male reproductive organs during sexual maturation in the Japanese common squid Todarodes pacificus. Nippon Suisan Gakkaishi 57:2237-2241

Ikeda Y, Sakurai Y, Shimazaki K (1991b) Development of female reproductive organs during sexual maturation in the Japanese common squid Todarodes pacificus. Nippon Suisan Gakkaishi 57:2243-2247 
Ikeda Y, Arai N, Sakamoto W, Kidokoro H, Yoshida K (1998) Microchemistry of the statoliths of the Japanese common squid Todarodes pacificus with special reference to its relation to the vertical temperature profiles of squid habitat. Fish Sci 64:179-184

Ikeda Y, Arai N, Sakamoto W, Mitsuhashi M, Yoshida K (1999) Preliminary report on PIXE analysis for trace elements of Octopus dofleini statoliths. Fish Sci 65:161-162

Ikeda Y, Okazaki J, Sakurai Y, Sakamoto W (2002) Periodic variation in $\mathrm{Sr} / \mathrm{Ca}$ ratios in statoliths of the Japanese common squid Todarodes pacificus Steenstrup 1880 (Cephalopoda: Ommastrephidae) maintained under constant water temperature. J Exp Mar Biol Ecol 273:161-170

Ito S, Okiyama M, Kasahara S (1965) Some consideration on the common squid, Todarodes pacificus Steenstrup, in the off-shore region of the Japan Sea. Bull Jpn Sea Reg Fish Res Lab 15:55-70

Kasahara S (1978) Descriptions of offshore squid angling in the Sea of Japan, with special reference to the distribution of common squid (Todarodes pacificus Steenstrup); and on the techniques for forecasting fishing conditions. Bull Jpn Sea Reg Fish Res Lab 29:179-199

Kasahara S, Ito S (1968) Studies on the migration of common squids in the Japan Sea. II. Migrations and some biological aspects of common squids having occurred in the offshore regions of the Japan Sea during the autumn season of 1966 and 1967. Bull Jpn Sea Reg Fish Res Lab 20:49-69

Kasahara S, Ito S (1972) Distribution and migration of common squid in the offshore area of the Japan Sea. Res Rep No. 57. Agriculture, Forestry, Fisheries Research Council, Tokyo, p 115-143

Kidokoro H (1999) Fishing grounds and fishing seasons of the Japanese common squid Todarodes pacificus in the Sea of Japan. In: Saito K (ed) Proc Squid Stock Ocean Conditions 1997. Tohoku Sea National Fisheries Research Institute Hachinohe Branch, Hachinohe, p 48-62

Kidokoro H, Hiyama Y (1996) Spatial variation in growth of Japanese common squid, Todarodes pacificus Steenstrup, in the Sea of Japan. Bull Jpn Sea Natl Fish Res Inst 46: $77-86$

Kidokoro H, Wada Y (1997) Statolith analysis of the hatching date of young Japanese common squid Todarodes pacificus Steenstrup sampled in Wakasa Bay in spring. Bull Jpn Sea Natl Fish Res Inst 47:105-110

Masuda F (1976) Can the elemental contents in skeletal carbonates be used as paleothermometer? J Geol Soc Jpn 82: $565-572$

Murata M (1983) On the distribution and the behavior under

Editorial responsibility: Otto Kinne (Editor),

Oldendorf/Luhe, Germany fishing lamps of young Japanese common squid Todarodes pacificus Steenstrup, in the offshore waters of northern Japan during spring and early summer. Bull Hokkaido Reg Fish Lab 48:37-52

Nakamura Y (1993) Vertical and horizontal movements of mature females of Ommastrephes bartramii observed by ultrasonic telemetry. In: Okutani T, O'Dor RK, Kubodera T (eds) Recent advances in cephalopod fishery biology. Tokai University Press, Tokyo, p 331-336

Nakamura Y, Sakurai Y (1991) Validation of daily growth increments in statoliths of Japanese common squid Todarodes pacificus. Nippon Suisan Gakkaishi 57:2007-2011

Okiyama M (1965) On the feeding habit of the common squid, Todarodes pacificus Steenstrup, in the off-shore region of the Japan Sea. Bull Jpn Sea Reg Fish Res Lab 14:31-41

Okutani T (1983) Todarodes pacificus. In: Boyle PR (ed) Cephalopod life cycles, Vol I. Species accounts. Academic Press, London, p 201-214

Radtke RL, Townsend DW, Folsom SD, Morrison MA (1990) Strontium:calcium concentration ratios in otoliths of herring larvae as indicators of environmental histories. Environ Biol Fish 27:51-61

Rodhouse PG, Robinson K, Gajdatsy SB, Daly HI, Ashmore MJS (1994) Growth, age structure and environmental history in the cephalopod Martialia hyadei (Teuthoidea: Ommastrephidae) at the Atlantic Polar Frontal Zone and on the Patagonian Shelf Edge. Antarct Sci 6:259-267

Sakurai Y, Ikeda Y (1994) Laboratory rearing methods of Todarodes pacificus for the ecological study of life cycle. In: Yatsu A (ed) Proc Squid Stock Ocean Conditions 1993. National Research Institute of Far Sea Fisheries, Shimizu, p 51-69

Shojima Y, Hotta H (1972) On common squid distribtuted in the East China Sea. Res Rep No. 57. Agriculture, Forestry, Fisheries Research Council, Tokyo, p 31-43

Smith SV, Buddermeier RW, Redalje RC, Houck JE (1979) Strontium-calcium thermometry in coral skeletons. Science 204:404-407

Soejima H (1993) Electron microanalysis: scanning electron microscope, X-ray micro-analyzer. Nikkan Kogyo Shinbunsha, Tokyo

Yamamoto T (1946) Eggs and larvae of common squid obtained in the Korean waters. Venus Jpn J Malacol 14: $228-240$

Yatsu A, Mochioka N, Morishita K, Toh H (1998) Strontium/calcium ratios in statoliths of the neon flying squid, Ommastrephes bartrami (Cephalopoda), in the North Pacific Ocean. Mar Biol 131:275-282

Submitted: July 31, 2001; Accepted: November 12, 2002

Proofs received from author(s): March 14, 2003 